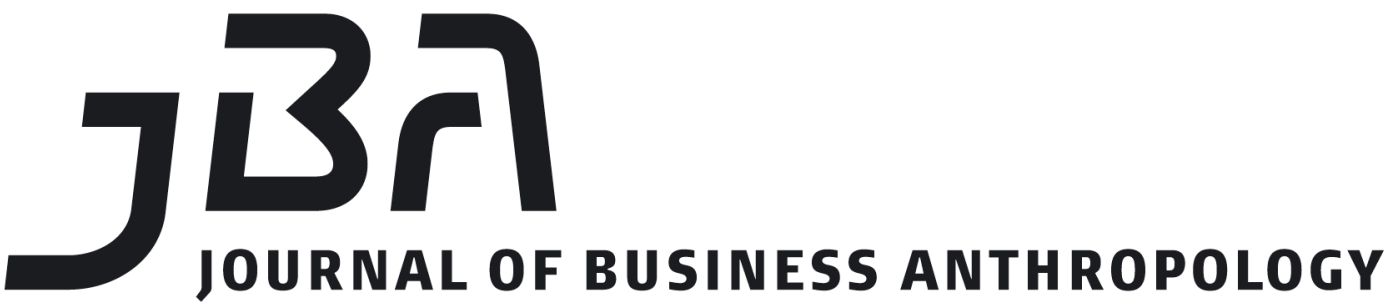

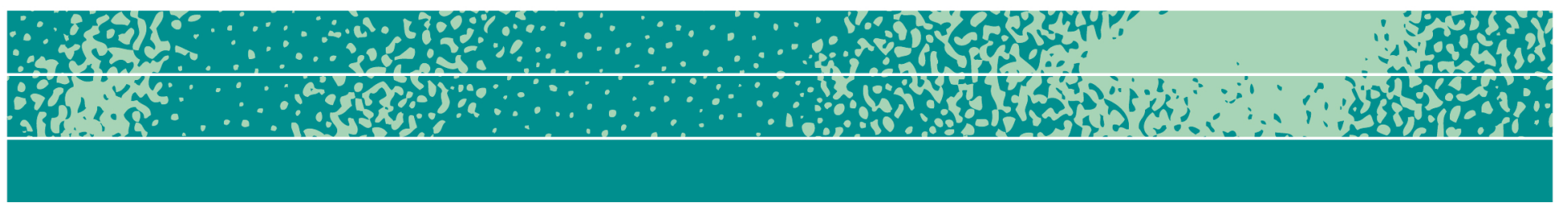

\section{Struggles and Strategies of Black Women Business Owners in the U.S.}

\author{
Taylor M. Jackson and Paromita Sanyal
}

\begin{abstract}
Black women start businesses at a rate above the national average. Yet, a revenue gap persists when compared to businesses owned by Black men and White men and women. Existing explanations for the differences in revenue highlight the lack of experience and limited access to start-up capital that constrain racial and gender minorities and also the type of industries in which they operate. Research specifically examining Black women business owners is very limited. In this article, we explore if Black women business owners' gender and racial identities pose challenges to running their businesses. We find that, because of their race and gender, Black women business owners contend with unique challenges that many entrepreneurs do not face. In-depth interviews reveal that they confront negative stereotypes held about them and, surprisingly, experience difficulties interacting with Black clients. These entrepreneurs cite navigation strategies that include monitoring self-presentation, adopting standards of excellence, and creating clear professional boundaries. This study suggests that Black women business owners might be spending more time than other business owners navigating challenges specifically linked to their identity, which seems to impact their business directly.
\end{abstract}

Page 1 of 22

JBA 8(2): 228-249

Autumn 2019

(C) The Author(s) 2019 ISSN 2245-4217

www.cbs.dk/jba 


\section{Key words}

Black women business owners, race, gender, stereotypes, selfpresentation, navigation, strategies

Long hours spent going over business plans, competing for start-up capital, and rubbing elbows with potential investors are images that dominate media portrayals of successful business ownership. The term "entrepreneur" conjures the image of a White man standing in front of concept boards delivering a pitch or developing a marketing strategy. Rarely do these images or portrayals include Black women business owners. Within mainstream media and academic literature, the narratives of Black women business owners are limited because they are not considered success stories by the conventional yardstick of profitability. Even among minority businesses, a revenue gap persists between Black women's and Black men's businesses. Despite Black women making up $56 \%$ of all Black-owned businesses, their businesses only generate an average of $\$ 27,753$ worth of annual receipts while Black men's businesses generate about $\$ 98,665$ (Barr 2015). We have little understanding of the obstacles Black women business owners face in establishing and maintaining their businesses or the strategies they use to overcome those obstacles.

In the literature, the label "entrepreneur" is reserved for owners of high growth companies, focused on innovation and profit-generation (Ruef 2010). Entrepreneurs are portrayed as individuals who set out to create a fortune through financially successful businesses (Braguinsky et al. 2012; Carland et al. 1984). In the U.S., a majority of small business owners tends to be White, male, has a diverse employment history, is older, and has a high level of educational attainment (Braguinsky et al. 2012 Carland et al. 1984). As a result, entrepreneurship is often framed as a White man's opportunity to pass on a business to his family and attain economic stability (Calas et al. 2009). For some scholars then, Black women do not measure up to this standard of success. Therefore, the term "business owner" is a more appropriate and less controversial label, since it is used to refer to individuals who might not be dominant in their field and are focused on personal growth (Carland et al. 1984). Black women business owners can be marginalized in the entrepreneurship literature due to these comparisons, limiting our understanding of their entrepreneurial endeavors. These gaps potentially contribute to the puzzle of why Black women's businesses are less profitable than their racial and gender counterparts.

This article examines the obstacles Black women business owners experience. Black women's identities as racial and gender minorities might impact their experiences as business owners in ways unique to their intersectional identity. Drawing on a set of interviews, we capture 
the complexity of operating businesses that get sidelined in favor of entrepreneurship narratives focused on innovations, profit margins and annual growth rates. We shed light on the negative stereotypes Black women business owners confront and the difficulties faced in interacting with clients of shared racial identity. We also reveal the range of strategies adopted for coping and navigating these unique challenges. This article deepens our knowledge of a scantily researched group of entrepreneurs in the U.S. by identifying key challenges and coping strategies and showing how they are linked to racial and gender identities.

\section{Black Businesses in the U.S.}

America's racist history has negatively impacted African Americans' opportunities for generational wealth. From slavery to Jim Crow, formal institutional barriers and discrimination have made it difficult for African Americans to gain upward economic mobility (Bogan \& Darity 2008). In this constrained context, Black Americans have always used working and self-employment as tools to navigate the struggles of racism, segregation, and discrimination (Butler 2005). Self-employment through a business venture can be a form of self-help to control one's livelihood (Bates 1997). In this way, Black Americans often start their own businesses to circumvent obstacles related to lack of education or experience needed to succeed in the formal economy (Robles \& Codero-Guzmán 2007). Black business owners are overrepresented in industries like personal services, transportation, food, and public utilities (Fairlie \& Robb 2007). In 2012, the top three industries for Black owned businesses were health care services, retail trade, and technical services (McManus 2016). Black women typically work and start businesses in the beauty industry, health services, and janitorial services (Collins 2008; Butler 2005; Hamilton 2014). None of these industries is as profitable as White men's businesses in the manufacturing industry or wholesale trade.

Black business owners usually lack key advantages that some White business owners enjoy. They possess fewer assets such as education and start-up funds for their businesses. Black business owners are also less likely to have a self-employed father (Fairlie \& Robb 2007) or a family member who owns their own business (Hout \& Rosen 2000). Intergenerational business ownership has positive effects for growth and success (Fairlie's 1999). This deficiency results in less training, sharing fewer resources and important information, and less human capital transfer over generations. Business viability is also tied to experience working in a related field; Black owners typically have fewer opportunities to gain these experiences (Loscocco \& Leicht 1993). Together, family business background, education, and start-up capital explain differences in White and Black owned businesses (Fairlie \& Robb 
2007).

Black business owners often account for success in ways other than profitability. Black women business owners report being pillars in their community as a measure of success and being able to provide a service to their community as a positive aspect of owning a business (Beggs \& Garmsmoke 1994; Harvey 2005; Robinson et al. 2007). There is a tendency for minority small business owners to target clients of shared racial backgrounds (Bates \& Robb 2014) In metropolitan areas, approximately $57 \%$ of firms in minority neighborhoods are owned by minorities, while over $80 \%$ of firms in nonminority neighborhoods are owned by White business owners (Bates \& Robb 2014). For example, Black barbershops and hair salons are among the most popular small businesses in addition to Latino-owned retail businesses serving primarily Hispanic populations. Some advantages include low levels of competition and barriers to start businesses in minority neighborhoods and low capital requirements. But, serving minority clientele increases rates of closure and translates to low levels of profit (Bates \& Robb 2014). Minority-owned businesses servicing predominately minority neighborhoods were more than $36 \%$ more likely to close within a fouryear period compared to non-minority owners servicing non-minority clients (Bates \& Robb 2008). Possible explanations for this negative relationship might lie in low levels of home purchase, crime, and negative neighborhood amenities.

\section{Women's Businesses: Limitations and Obstacles}

Some of the limitations and obstacles women business owners face are similar to those experienced by Black business owners: lack of experience, capital, and resources to generate profits comparable to White men (Robles \& Cordero-Guzmán 2007). But there are also different constraints that women and men business owners face. Women's businesses tend to be less profitable and successful than businesses owned by men. One explanation for this revenue gap is the type of businesses women typically own (Loscocco \& Robinson 1991). Femaletyped businesses like retail, food service, and social services tend to generate fewer receipts than businesses owned by men who typically operate businesses in finance, manufacturing, and real estate. Even when women own firms in industries dominated by men, they tend to do so in sectors that focus on decorating, paperhanging, and painting, which still generate lower profits. A lack of managerial experience, limited access to start-up capital, and family responsibilities also impact the profitability of women's businesses (Parker 2018). Women are less likely than men to have had experience managing cash flow, acquiring capital, or educational or training programs to prepare them for the struggles of business ownership (Loscocco \& Robinson 1991). Taking care of children and 
managing household responsibilities also directly impact business ownership for women (Hundley 2001). Family structure has the potential to impact commitment and time spent devoted to business ownership.

Overall, women struggle operating their businesses because of lack of experience, constrained access to resources, and juggling work and family life. These obstacles limit the types of businesses they are able to own, their opportunities for growth as well as profit, the amount of timer per week they can devote to the business, and their ability to maintain their firms. Although men face challenges keeping their businesses open, women's experiences with business ownership are constrained by their marginalized status within the broader labor market (Loscocco \& Robinson 1991).

\section{Black Women in Business}

Very few studies have examined the business ownership experiences of Black women exclusively. Black business owners are sometimes able to use race to their advantage for certain business practices. For example, Black beauty aids use their ethnic resources to build rapport and cultivate business connections with other Black business owners in the hair industry because salon owners and barbers feel more comfortable buying supplies from distributors that looked like them (Silverman 1999). Black women business owners are also able to adopt helping ideologies, mentor other Black women, and create safe spaces for women of color through their businesses (Harvey 2005). Although they tend to have less diverse social networks (Renzulli et al. 2000), understanding how Black women business owners capitalize on shared racial identities informs how Black women are able to circumvent challenges presented by their social networks.

We are left wondering if Black women face unique challenges that get lost when they are included in analyses focused on women in general or racial minorities as a whole. Key questions remain to be addressed. For instance, the literature suggests that racism and sexism push Black women out of corporate America (Harvey 2005). Stereotypes, such as controlling images, justify the marginalization and oppression of Black women and can create hostile work environments (Collins 2008). Black women are often seen as incompetent or less intelligent than their White counterparts in predominantly White workplaces (Hall et al. 2012). The ways Black women adopt survival strategies to navigate racism and sexism have the potential to impact how successful their work experiences are. Black women cite walking away, praying, and trying to manage the pace of the stressor as coping mechanisms for workplace stress (Hall et al. 2012). Professional Black women attempt to adhere to Western cultural norms of corporate spaces (Durr \& Wingfield 2011), which ultimately uphold standards of whiteness. By attempting to align 
themselves with the workplace culture, Black women engage in emotional labor that can be taxing and stressful to manage in already high-pressure occupations. If they present themselves as assertive so that no one takes advantage of them, they might risk trading one controlling image for a different one in the workplace (Wingfield 2007).

Do Black women escape these types of racism and sexism and the negative attributions of stereotypes by becoming business owners? What coping strategies do they adopt in the world of business to navigate these challenges? Our study addresses these questions and fills the gap. We detail some of the stereotypes that confront Black women business owners and reveal how they respond to the prevailing stereotypes through their business practices and self-presentation. Understanding the various techniques Black women business owners use to cope with stress and discrimination allows us to situate their experiences within a broader context. If Black women are spending more time holding their tongues, monitoring their self-presentation, and attempting to merge different social positions as they are known to do in adapting to White workspaces (Bell 1990; Durr \& Wingfield 2011), their experiences with success and business ownership might differ from other business owners.

\section{Data \& Methods}

\section{Data Collection}

We conducted semi-structured interviews with 20 Black women business owners from Florida, Indiana, Missouri, Georgia, and Virginia. Semistructured interviews provide an opportunity to examine experiences that are lost in quantitative studies on business ownership (Baker et al. 1997). Six of the interviews were conducted in person in a mid-sized northern city in Florida. These interviews took place at coffee shops and at women's offices. Due to the geographic location of the other Black women, the rest of the interviews took place over the phone. Phone interviews were more convenient for interviewees. Many of them participated in the interview while they were traveling for work, before they started their workday, during lunch, or while they were picking their children up from school.

We contacted the Chamber of Commerce, small business initiatives, and business development specialists in the area to recruit study participants. We posted recruitment information on social media platforms targeted to small businesses, Black graduate students, and listservs. We used snowball sampling to recruit new participants based on interviewee suggestions. Recruiting participants was difficult because $75 \%$ of them held full-time positions in 9-to-5 jobs in addition to operating their own businesses. Many of the interviewees also had families. Online listservs and social media groups were the most successful recruiting tools. The online platforms contained groups 
specifically targeting Black women business owners so that information about the study was distributed to potential participates quickly.

Interview questions examined the women's struggles getting their businesses off the ground and their overall experiences as business owners. The interview questions related to the start-up process, their lives as business owners, specific challenges they faced, and particular strategies they utilized to maintain their businesses. We also asked questions related to the number of employees and partners the interviewee had, as well as estimates of their annual revenue. Interviews typically lasted anywhere from 35 to 95 minutes. All interviews were tape-recorded and later transcribed for coding. Names that appear in the analysis are pseudonyms.

Before interviewing interviewees over the phone, the first author (Jackson) did not disclose her racial or gender identity. ${ }^{1}$ Nevertheless, interviewees very likely identified the first author as a Black woman based on their responses and language. Interviewees were comfortable engaging in conversations with her and referring her to other Black women in their networks. They used language that the first author was familiar with and shared experiences that she had the language and experience to understand. For example, interviewees used phrases like, "I'm sure you know what I mean", "You know how it is", or "You know, I'm just gonna be straight up with you". Some interviewees discussed how other interviewers might feel about their answers in relation to stereotypes and race relations. The first author was also able to follow cultural references to \#BlackGirlMagic or the use of slang like "chile" (a play on the word "child", often used as an interjection) or "the hook-up" (a favor). The first author used her identity as a Black woman to ask probing questions about interviewees' experiences with business ownership.

The age of study participants ranged from 27-60. Women owned various businesses from hair care and fitness to information technology and real estate. The average length of business ownership was approximately three years, reflective of a broader pattern; in 2014, 14\% of U.S. minority businesses had been operating for less than two years (Huntley-Hall 2017). Also, consistent with data from the National Women's Business Council (2012), most of our interviewees had no employees. Of the 20 women interviewed, 16 were simultaneously employed somewhere other than their own businesses. Financial analyst, marketing strategist, and educator were some of the positions in which the women worked. Half of the interviewees held graduate degrees. Their educational attainment aligns with current statistics that demonstrate

\footnotetext{
${ }^{1}$ First author conducted all the interviews.
} 
Black women continue to be the most educated group in America, taking into account race and gender (National Center for Education Statistics 2017).

Table 1. Descriptive Characteristics of Black Women Business Owners

\begin{tabular}{|c|c|c|c|c|c|c|}
\hline Pseudonym & Age & Location & Education Level & Type of Business & $\begin{array}{c}\text { Length of } \\
\text { Business } \\
\text { Ownership }\end{array}$ & $\begin{array}{c}\text { Are they } \\
\text { employed } \\
\text { elsewhere? }\end{array}$ \\
\hline Nadia & 47 & Indianapolis, IN & Graduate & Information Technology & 1 month & Yes \\
\hline Vivian & 34 & Tallahassee, FL & Undergraduate & Dance Studio & 8 months & Yes \\
\hline Tatiana & 27 & $\begin{array}{l}\text { Tallahassee, FL } \\
\text { Bloomington, }\end{array}$ & High School & Lifestyle brand & 8 months & Yes \\
\hline Fallon & 27 & IN & Graduate & Lifestyle brand & 1 year & Yes \\
\hline Victoria & 45 & Kansas City, M0 & Undergraduate & Hair care products & 2 years & Yes \\
\hline Audrey & 31 & Tampa, FL & Undergraduate & Make-up & 2 years & Yes \\
\hline Desiree & 33 & Tallahassee, FL & Undergraduate & $\begin{array}{l}\text { Writing/Editing } \\
\text { Publishing }\end{array}$ & 2 years & Yes \\
\hline Giselle & 40 & Tampa, FL & Graduate & Retail & 2.5 years & No \\
\hline Carmen & 39 & Tampa, FL & Graduate & Life \& Leadership Coach & 3 years & Yes \\
\hline Cynthia & 40 & Tallahassee, FL & High School & Non-profit & 3 years & Yes \\
\hline Tracee & 34 & Atlanta, GA & Undergraduate & Financial services & 3 years & Yes \\
\hline Layla & 28 & Tallahassee, FL & Undergraduate & Magazine & 3 years & No \\
\hline Natalie & 39 & Atlanta, GA & Graduate & Mental health services & 3 years & Yes \\
\hline Kimberlee & 49 & Tallahassee, FL & Graduate & Fitness and cheer studio & 3 years & Yes \\
\hline Lynn & 39 & Tallahassee, FL & Undergraduate & Retail & 3 years & No \\
\hline Monet & 40 & Tallahassee, FL & High school & $\begin{array}{c}\text { Zumba fitness business } \\
\text { Small Business }\end{array}$ & 4 years & Yes \\
\hline Simone & 30 & Houston, TX & Graduate & Consulting & 4 years & No \\
\hline Mackenzie & 40 & Tampa, FL & Graduate & Sports consulting group & 5 years & Yes \\
\hline Hayden & 35 & Tampa, FL & Graduate & Afterschool enrichment & 6 years & Yes \\
\hline Sloan & 60 & Alexandria, VA & Graduate & Real estate & 10 years & No \\
\hline
\end{tabular}

\section{Data Analysis}

The framework of intersectional analysis that combines race, gender, and class alerts us to the possibility that Black women's unique configurations of race and gender might entail experiences as business owners that are distinct from women of other races, including those of other minorities (Collins 2008; Crenshaw 1989). Guided by this framework, we utilized inductive coding to highlight broad themes for our analytic strategy (Charmaz 2014). After coding several interviews, we developed central themes such as stereotypes, interactions with clients, time constraints, economic mobility, and resources to combat challenges. Then, we created 
sub-themes within the original codes that we initially created to capture a more detailed picture of the business owners' experiences. These codes included drawing clear boundaries, self-presentation, and internalizing controlling images. We sampled to redundancy. After coding 20 interviews, we found that core themes and narratives were being repeated.

\section{Stereotypes: Not "Someone like Donald Trump"}

Black women business owners faced double disadvantages stemming from their intersectional identities. They did not fit the stereotypical image of an entrepreneur or a business-owner. Deviating from these stereotypes led to their marginalization from mainstream discourses and also to public misconceptions. Added to this, their intersectional identity of being a Black woman triggered socially held negative images and perceptions among their clientele and associates. These stereotypes affected the ways Black women were viewed by others and influenced their self-identity as business owners as well as their business practices. When asked what kind of perceptions they felt society had about Black women business owners, 70\% (14) of interviewees mentioned stereotypes such as having bad attitudes, being angry, being intimidating, and acting unprofessionally. Layla (28, owner of a magazine) discussed "controlling images" (Collins 2008) she thinks exist about Black women business owners. Layla said:

I noticed the stereotypical image of the angry Black woman. You're single, you're very bossy, and that can automatically translate into you're a bitch. Or, that we don't get to the top and that we didn't do it all by ourselves. We have an attitude. That we're not running it the way that it should be.

Layla described how other people have ideas about how Black women business owners structure their lives - emphasizing the stereotype that Black women prioritize their careers over their family and personal lives. Such negative portrayals also imply that Black women business owners are domineering and difficult to interact with.

Interviewees mentioned people questioning their credibility as business owners and faced stereotypes regarding the legality and integrity of their businesses. Lynn (39, owner of a boutique) discussed how customers questioned her business practices:

I'm sure somewhere down the line someone is probably thinking something. You know, that maybe because I am a person of color servicing other people of color, there may be some illegal activity with this merchandise. Or, maybe I got it off the back of a truck that was just stolen.

Lynn expressed that owning a business servicing people of color 
in a segregated city affects the perceptions others have about her business practices. She also mentioned that other business owners (she did not mention their races) within her area were not questioned in the same way.

The interviewees indicated how the general public stereotypically views Black women business owners as hair salon owners, a stereotype that fails to recognize the diversity of Black businesses as well as their interests in other industries. Some interviewees also felt they were left out of mainstream narratives of business ownership. Fallon (27, owner of a lifestyle brand) discussed this point:

Entrepreneurship is still this business graduate White man with a blue suit and red tie. Someone like Donald Trump, so that's what they see when they see entrepreneurship. Since his presidency, and even before his presidency, White supremacy doesn't see anyone but themselves [White people]. That doesn't leave space for other black and brown bodies who want to be able to have the same opportunities.

Fallon believes it is imperative to challenge the dominant constructions of business ownership by promoting the kinds of entrepreneurial experiences that center Black business owners. Her discussion also highlights the opportunities from which Black women might be barred because they are often left out of mainstream discourse on entrepreneurship. For example, when asked who was represented within entrepreneurship discourse Mackenzie (40, owner of a sports consulting firm) stated:

If I had to rank them, it would be White male, Black male, Becky [White female] and then African American women, so I definitely feel like we are left out. So, I definitely feel like Black men are part of the conversation, so people are like oh there's probably a Black female out there too.

In this way, public conceptions regarding Black women business owners seem to influence their self-identity and constrain how they operate their businesses.

Interviewees' businesses were also stereotyped as targeting Black clientele exclusively, even when not intended. Hayden (35, owner of a program geared towards young girls' educational and social development) discussed how the choice of the word "diva" as part of her business name was limiting her clientele because of its association with Black girls and its negative behavioral connotations. She said:

So, when they see the word 'diva' it's not a positive connotation. You know she's a diva because she talks too much, or she has an attitude. Unfortunately, those types of stereotypes do exist and when you hear 'princess' you think more of, you know maybe a 
Caucasian girl. Unfortunately, when people hear the word 'diva' they think of a Black girl, let's be honest.

The word "diva" appeared in the company's mission statement and marketing strategy. Hayden was having a difficult time marketing to a diverse clientele because of the term's negative connotation. Eventually she plans to replace the word diva with something more generic. For now, she feels it is necessary to challenge these negative stereotypes about Black girls and continue to use the name.

\section{Navigating Stereotypes}

Performing to the Pressure and Cultivating Personal Strength: "Not allowed to crack"

Black women business owners chose to address stereotypes in a range of ways. Five out of 20 interviewees said stereotypes did not add any stress or affect the way they conducted their businesses. In fact, some framed facing stereotypes as a positive opportunity to demonstrate the capabilities and competency of Black women. Victoria (45, owner of a hair care line) discussed the productive ways of navigating stereotypes about Black women business owners:

I'm just one person and I think if you can walk and talk a certain way and interact and do business a certain way that makes the next person feel like they can do that too, so it kind of raises the bar for everyone and makes them feel like they can do that too.

Victoria chose to use stereotypes as a motivation for her success as well as an opportunity to inspire other Black women. However, she did acknowledge that she had to be mindful of her actions and present herself in a certain way to demonstrate professionalism and competency. This attention to self-presentation and heightened awareness of the importance of impression management was shared by some of the other interviewees.

For fifteen of the 20 owners, internalizing stereotypes negatively impacted their everyday experiences and how they coped with stress from their business. Interviewees mentioned the strong Black woman schema. This stereotype assumes that Black women are, "strong, independent, and self-sacrificing" (West 2016). Chloe (27, owner of a lifestyle brand) discussed how sometimes being portrayed as a strong Black woman made it difficult to operate and manage her business:

It does put some pressure on you because you think you're not allowed to crack. So, I kinda do that privately. But it does make you feel like, OK I can't mess up I have people watching me. I've got people doubting me, so it's in the back of my mind.

The strong Black woman schema has the potential to make asking 
for help more difficult for Black women business owners. Black women are more likely to suffer in silence because stereotypes influence expectations, that is, they are supposed to be able to handle business and life challenges without fail.

Standards of Excellence: "It's gonna be better than what you get from Becky"

Interviewees were aware that stereotypes held by others could affect interactions with clients, support from consumers, and the overall image of their businesses. Sixty percent (12) of interviewees adopted high standards of excellence and professionalism to navigate stereotypes that could affect their business practices. All of the interviewees highlighted how they made sure to offer quality customer service and conduct themselves in a professional manner so that they could maintain good relationships with their clients and fellow business owners.

Mackenzie described how she conducted business, so others would know her brand was professional and provided quality service:

Because we have a certain standard of excellence that we try to achieve you know we try to get rid of that stigma that Black people are never on time. You know it's not going to be good: 'They're always late.' Like, what you get from us is going to be topquality. It's probably going to be better than what you're going to get from Becky [a stereotypical White woman). You know what I mean right?

Mackenzie emphasized how she incorporates professionalism and high-quality service in her business to combat stereotypes about Black businesses. This reference to an imaginary "Becky" suggests that she feels that clients are comparing her and the quality of her services to White women business owners and their services. While this study was not designed to compare Black and White business owners' experiences, Black women believe the comparison was relevant - that White women business owners do not experience this pressure or burden from being compared to their Black counterparts.

Self-presentation and Impression Management: "I'm not Bon Qui Qui from down the street"

Black women business owners monitor their presentation of self to compete with business owners of other races and other women.

Interviewees were cognizant of their appearance, mannerisms, and speech when interacting with clients or other business owners. Audrey (31, owner of a make-up brand) discussed how she makes sure to keep her appearance simple when conducting business: 
I didn't do my crazy hair colors when I was doing business. So, I try to be very sleek, very professional, and show that I am the type of businesswoman that they want. I'm not Bon Qui Qui from down the street. That's not the impression that I want to give.

Audrey's mention of Bon Qui Qui has important racial and class connotations. ${ }^{2}$ The character is a loud, unprofessional woman working as a fast food employee. Although the actress playing the character is Mexican and Native American, Bon Qui Qui is often used as a stereotypical name for a "ghetto" Black woman. Her tone and attire are scripted to exaggerate perceptions of Black culture. Audrey uses this popular culture reference to highlight how susceptible Black women are to being judged by their appearance compared to White women. These negative stereotypical images of Black women circulating in popular culture make women like Audrey hyper aware of the importance self-presentation and impression management. In this way, some Black women business owners felt pressure to succeed because of their identities as Black women.

An extreme form of business impression management involved erasing racially identifiable markers from Black women-owned business. Hayden revealed this strategy when she considered removing the word "diva" from her business' name. Describing how she felt her race impacted the demographic of her clients and, ultimately, her ability to generate revenue, she said:

Now, changing the name [taking out the word 'diva'] is not going to solve all of our problems, and our new director that we interviewed went to my website and suggested that we take our photos off of the website.

Keeping their identities hidden by making themselves invisible is a strategy of compromise that some Black women business owners consider to increase the diversity of their clientele and generate more revenue. This strategy suggests that minimizing their racial identity is integrated into the business strategies of some Black women owned businesses to combat clients' preconceived notions about such businesses.

\section{Interacting with Clients: "I'll get you next week!"}

Black women business owners faced challenges interacting with their clients because of shared racial identities. Half of the interviewees

\footnotetext{
${ }^{2}$ The character Bon Qui Qui is a character first introduced on a comedy skit on Madtv. It can be argued that the satirical character demonstrates mannerisms and speech of a stereotypical Black woman, displaying a caricature of Black women's behavior and appearance. The character is also used to portray stereotypes associated with service workers.
} 
explicitly mentioned difficulty interacting with their clientele. Most of these women's networks, social spaces, and clientele were made up of other people of color. However, some of them faced situations where clients took advantage of familiarity because of shared racial identity which blurred the lines between professional and personal relationships. Monet (40, owner of a Zumba company) recalled the time a customer tried to pay a discounted rate for a class:

So, before I was only charging $\$ 3$ a class, and you know you don't know your worth, but a lady came into class late. It was only like 30 minutes in and she asked my sister if she could only pay $\$ 1.50$ since she's only going to be there for half the time. I love my people. I do. But who asks that? You don't go to the movies and ask can I just pay half of it, and she was very serious.

Monet used the phrase, "my people" to signify race was a factor in the interaction. Later in the interview, Monet also mentioned that she did not think the Black customer would have asked a White business owner for the same type of discount. Sharing a racial identity often complicated the relationship business owners had with their clients.

Since owners were servicing their friends, family, and community members, clients would get comfortable asking for special treatment in the form of late payments or paying in installments. Interviewees tried to be sympathetic to financial need but expressed doubts that their clients would walk into a White-owned business and ask for the differential treatment. Kimberlee (34, owner of a Fitness studio) mentioned the blurred lines in her interview:

We spend so much time with them. We get to know them, they get to know us. You know they're holding my baby, so you know it becomes like a family ...because I think black businesses we get real comfortable like our clients get really comfortable with the, 'Oh, I'll get you next week.' You wouldn't do that to certain businesses.

Kimberlee explained how she felt like a bill collector when interacting with her clients. She expressed anxiety about having to tell her clients they had to pay on time. Part of her apprehension was tied to the close relationships she had with many at her fitness studio. However, Kimberlee acknowledged that to keep her business running she had to make her clients pay on time.

In contrast, some interviewees felt sharing a racial identity with their clients positively impacted interactions with them. Carmen $(39$, a professional life coach) saw interacting primarily with women of color as an advantage:

The first thing that you see [on my company webpage] is my beautiful Black face and if you're not okay with that then you're 
probably not going to choose me. It was an active choice absolutely. I've had a lot of Black women choose me because I have a picture of me in my bio and they said, 'I chose you because you're Black, and I'm so happy to see you're one of my three choices [options for potential life coaches].'

Carmen suggested that being a Black woman was an opportunity to relate to her Black female clients and provide a level of comfort that actually enhanced her business. Her viewpoint indicates that Black women business owners vary in experiencing the effect of shared race on client interactions. Some felt that disclosing their race would constrain the demographic of their clientele, while others were able to understand the needs of their Black clients better as a result.

\section{Navigating Client Interactions}

Setting Professional Boundaries: "Don't make it so casual"

Black women business owners conducted themselves in a professional manner to combat stereotypes and to set clear boundaries with clients. Thirty-five percent (7) of interviewees mentioned setting clear boundaries to signify their need for professional relationships with their clients. Giselle (40, in retail) discussed how she made sure to separate business and personal relationships when she was interacting with clients:

You don't make it so casual. You can be friendly for sure, but just to be clear you know making sure that this is separating it from, 'Hey, Julie, this is a business this is how much it is, this is what we do, here is the invoice, here's the paperwork and here's what I need you to sign for us to move forward.' So, it's just setting those boundaries and remaining professional about keeping it the way you would keep a business with a stranger.

Desiree (33, owner of a publishing company) also mentioned making her expectations known upfront:

One of the things that I try and do to circumvent that [problem] is to be very transparent. I'm very adamant about letting my clients know how much it's going to be at the beginning and what they can expect from me. I don't want them to have to guess or feel like I'm trying to nickel and dime them, and I find that that has made the process much smoother and makes it easier for the process.

Black women business owners incorporated creating clear boundaries into their adaptive strategies for their businesses. To overcome obstacles related to client interactions, interviewees often had to lay the groundwork for professionalism early on during the formation of client relationships. 


\section{Discussion}

Research on entrepreneurship and business ownership usually examines experiences of women (Parker 2018; Hundley 2001) and racial minorities (Fairlie \& Robb 2007) separately or aggregates them together. These approaches fail to account for the effect of stereotypes on Black women specifically. Given the extensive literature on "controlling images" applied to Black women (Collins 2008; Reynolds-Dobb 2008; West 2016), we found that stereotypes pose challenges for Black women owners.

Our findings contribute to the literature on barriers to business ownership by examining how race and gender intersect to create specific challenges for Black women. Women, in general, face challenges starting and sustaining their own firms due to limited managerial experience and difficulty securing start-up capital and institutional funds (Parker 2018; Loscocco \& Robinson 1991) and because of juggling family demands (Hundley 2001). Women also tend to own businesses in service industries that generate less revenue than business in finance, real-estate, and manufacturing (Parker 2018). Black owners operate businesses in personal services, transportation, and food industries (Fairlie \& Robb 2007). And lack of education, training, and limited knowledge of business lead to less revenue and success for Black businesses. None of these challenges recorded in the literature is related to the intersectional identities of Black women, which must also be considered.

We find Black women business owners face unique challenges related to their intersectional identities as racial and gender minorities. Despite a long history of self-employment and small business, Black women still do not fit the contemporary public stereotype of an entrepreneur. Moreover, because of their intersectional identities, they have to battle negative stereotypes present in public perception and popular culture that threaten to tarnish their professionalism and public image among their clients. Most of the interviewees felt the oppressive weight of being negatively judged or ascribed with those stereotypes.

Black women business owners face stereotypes regarding their personality and professionalism drawn from commonly held "controlling images" (Collins 2008; Reynolds-Dobbs et al. 2008) that affect their experiences as business owners. Stereotypes of being unprofessional, intimidating, and having bad attitudes influence the ways Black women business owners present themselves, interact with clients, and manage their business practices. Although White women also experience stereotypes related to competency and intelligence in the workplace (Heilman et al. 2004), race and gender contribute to controlling images for Black women in unique and more severe ways (Reynolds-Dobb et al. 2008). Black women's tone of voice, style of dress, hairstyles, and demeanor can be read as threatening or unprofessional. Even the forms of marketing and promotional images Black women utilize on their business 
websites and decisions regarding making themselves (in)visible and (un) identifiable can be consequential. Their choices can limit their clientele and put a constraint on their profitability and business expansion. Therefore, dealing with stereotypes and unique decision-making challenges add a layer of stress to business ownership for Black women that other business owners are unlikely to face.

One of the questions that motivated this research was whether business ownership provides an escape from challenges in the formal labor market and hostile work environments of corporate America for Black women. We found persistent negative stereotypes and the need for impression management through presentation of self (Goffman 1959) as we followed Black women from the formal labor market into selfemployment. Previous research suggests Black women leave corporate America to alleviate challenges, exchanging hostile work environments to become business owners (Boyd 2000). However, our findings show that stereotypes about Black women persist even when they become owners. As a result, the work experiences of Black women business owners are affected in ways similar to those of Black professional women in the labor market. A surprising finding is that instead of receiving pressure from White employers, Black women business owners are also stereotyped by those with whom they share their racial identity.

Shared racial identity and close ties with Black clientele can benefit Black women business owners but can also complicate client relationships. Clients actually seek out Black women because they feel more comfortable interacting with them in comparison to White business owners. Past research has also demonstrated that racial minorities experience advantages from operating their businesses in minority neighborhoods (Silverman 1999). We find evidence to support previous research that finds minority and ethnic entrepreneurs treat their clients like close friends and family (Dallafar 1994). Although Black women business owners are able to relate to their clientele, familiarity and comfort sometimes prompt clients to ask for discounts and request special treatment like delayed payments, which can be detrimental for business profitability and growth. These types of obstacles may be a reason why minority firms servicing minority clients are less viable than their White counterparts (Bates \& Robb 2008). Maintaining professional interactions with Black clients (e.g., refusing such requests, insisting on timely repayment, collecting on late payments) become challenging because of a sense of familiarity and shared membership in a community. They try to establish boundaries between personal interactions and business transactions from the start of their business relationships with their Black clientele. As a result, Black women business owners have to do added work in balancing professional and personal relationships to continue operating their businesses successfully. 


\section{Conclusion and Future Research}

Black women's racial and gender identities affect their business endeavors and force them to navigate preconceived notions that make operating their businesses more difficult. They are still met with negative stereotypes that make building clienteles and establishing professional relationships more difficult than their racial and gender counterparts. Strategically adopting standards of excellence and establishing professional boundaries is time intensive and adds to the stress of daily entrepreneurial practices. Therefore, it is important for us to include these obstacles in how we conceptualize barriers to business ownership.

These narratives help us broaden our understanding about what it means to be a business owner and chip away at the conventional image of a white man in a blue suit. Self-employment continues to be discussed as a way to financial freedom. Keeping the obstacles discussed in mind, we question whether business ownership can really lead to wealth accumulation and if increased business ownership is a big enough win for Black women. Instead of thinking of business ownership as an automatic escape and pathway to economic freedom, this study demonstrates that becoming a business owner does not eliminate obstacles to economic success for Black women.

As Black women continue to start businesses in a variety of industries, small business initiatives, workshops, and programs must keep in mind how stereotypes, and difficulties interacting and managing relationships with racial minority clients, can impact the start-up process and day-to-day operations. Conversations on entrepreneurship must also broaden the scope to include Black women and their types of businesses and acknowledge the obstacles they face. Black women business owners more seasoned in their entrepreneurial journey can serve as mentors, offering guidance and support on potential obstacles.

More research is needed to understand how Black women's businesses translate to economic mobility. It is difficult to tell whether the business owners in the current study faced specific challenges generating revenue because of being Black women-owned businesses or because the businesses had been operating for less than five years. We recognize the limitation of the size as well as the regional aspects of our sample. Comparative and cross-regional studies are needed to paint a more complete picture of the state of Black women's business ownership. Future studies should directly compare Black women to women and men from other racial groups to demonstrate how these obstacles might manifest differently for other business owners. Longitudinal studies would also be valuable for examining how Black women are able to grow their businesses over time. 


\section{References}

Barr, M. 2015. Minority and Women Entrepreneurs: Building Capital, Networks, and Skills. The Hamilton Project 1-22. Washington, D.C.

Baker, T., H. E. Aldrich, and N. Liou. 1997. Invisible Entrepreneurs: The Neglect of Women Business Owners by Mass Media and Scholarly Journals in the USA, Entrepreneurship and Regional Development 9(3):221-38. https://doi.org/10.1080/08985629700000013

Bates, T. 1997. Race, Self-employment, and Upward Mobility. Baltimore, MD: Johns Hopkins University Press.

Bates, T., \& Robb, A. 2008. Analysis of Young Neighborhood Firms Serving Urban Minority Clients, Journal of Economics and Business, 60(1-2): 139148. https://doi.org/10.1016/i.jeconbus.2007.09.004

Bates, T., \& Robb, A. 2014. Small-business Viability in America's Urban Minority Communities, Urban Studies 51(13): 2844-2862. https://doi.org/10.1177/0042098013514462

Beauboeuf-Lafontant, T. 2003. Strong and Large Black Women? Exploring Relationships between Deviant Womanhood and Weight, Gender \& Society 17(1): 111-121. https://doi.org/10.1177/0891243202238981

Beggs, J., Doolittle, D., \& Garmsmoke, D. 1994. Entrepreneurship Interface: Linkages to Race, Sex, and Class, Race, Sex \& Class 35-51.

Bell, E. L. 1990. The Bicultural Life Experience of Career-oriented Black Women, Journal of Organizational Behavior 11(6): 459-47. https://doi.org/10.1002/job.4030110607

Braguinsky, S., Klepper, S., \& Ohyama, A. 2012. High-tech Entrepreneurship, The Journal of Law and Economics 55(4): 869-900. https://doi.org/10.1086/666488

Bogan, V., \& Darity Jr, W. 2008. Culture and Entrepreneurship? African American and Immigrant Self-employment in the United States, The Journal of Socio-Economics 37(5): 1999-2019. https://doi.org/10.1016/i.socec.2007.10.010

Butler, J. S. 2012. Entrepreneurship and Self-help among Black Americans: A Reconsideration of Race and Economics. Albany, NY: SUNY Press.

Calas, M. B., Smircich, L., \& Bourne, K. A. 2009. Extending the Boundaries: Reframing 'Entrepreneurship as Social Change' through Feminist Perspectives, Academy of Management Review 34(3): 552-569. https://doi.org/10.5465/amr.2009.40633597

Carland, J. W., Hoy, F., Boulton, W. R., \& Carland, J. A. C. 1984.

Differentiating Entrepreneurs from Small Business Owners: A Conceptualization, Academy of Management Review 9(2): 354-359. https://doi.org/10.5465/amr.1984.4277721 
Charmaz, K. 2014. Constructing Grounded Theory. Newbury Park, CA:

Sage.

Collins, P. H. 2008. Black Feminist Thought: Knowledge, Consciousness, and the Politics of Empowerment. New York, NY: Routledge.

Crenshaw, K. 1989. Demarginalizing the Intersection of Race and Sex: A Black feminist Critique of Antidiscrimination Doctrine, Feminist Theory, and Antiracist Politics, University of Chicago Legal Forum 1989(1): 139167.

Dallalfar, A. 1994. Iranian Women as Immigrant Entrepreneurs, Gender \& Society 8(4): 541-561. https://doi.org/10.1177/089124394008004005

Durr, M., \& Harvey Wingfield, A. M. 2011. Keep your 'N' in Check: African American Women and the Interactive Effects of Etiquette and Emotional Labor, Critical Sociology 37(5): 557-571.

https://doi.org/10.1177/0896920510380074

Fairlie, R. W., \& Robb, A. M. 2007. Why are Black-owned Businesses Less Successful than White-owned Businesses? The Role of Families, Inheritances, and Business Human Capital, Journal of Labor Economics 25(2): 289-323. https://doi.org/10.1086/510763

Goffman, E. 1959. The Presentation of Self in Everyday Life. Garden City, New York, NY: Anchor Books.

Hall, J. C., Everett, J. E., \& Hamilton-Mason, J. 2012. Black Women Talk about Workplace Stress and How They Cope, Journal of Black Studies 43(2): 207-226. https://doi.org/10.1177/0021934711413272

Harvey, A. M. 2005. Becoming Entrepreneurs: Intersections of Race, Class, and Gender at the Black Beauty Salon, Gender \& Society 19(6):789-808. https://doi.org/10.1177/0891243205280104

Heilman, M.E., Wallen, A.S., Fuchs, D., \& Tamkins, M.M. 2004. Penalties for Success: Reactions to Women Who Succeed at Male Gender-Typed Tasks, Journal of Applied Psychology 89(3): 416-427.

https://doi.org/10.1037/0021-9010.89.3.416

Hundley, G. 2001. Why Women Earn Less than Men in Self-employment, Journal of Labor Research, 22(4): 817-829. https://doi.org/10.1007/s12122-001-1054-3

Huntley-Hall, N. 2017. Number of Minority-Owned Employer Firms Increased in 2015, United States Census Bureau. Washington, D.C.

Hout, M., \& Rosen, M. 2000. Self-Employment, Family Background, and Race, Journal of Human Resources 35(4): 670-692.

https://doi.org/10.2307/146367

Loscocco, K. A., \& Leicht, K. T. 1993. Gender, Work-Family Linkages, and Economic Success among Small Business Owners, Journal of Marriage and the Family 55(4): 875-887. https://doi.org/10.2307/352769 
Loscocco, K. A., \& Robinson, J. 1991. Barriers to Women's Small-business Success in the United States, Gender \& Society 5(4): 511-532. https://doi.org/10.1177/089124391005004005

McManus, Michael, and Regulatory Economist. 2016. Minority Business Ownership: Data from the 2012 Survey of Business Owners. U.S. Small Business Administration Office of Advocacy. Washington, D.C.

National Women's Business Council. 2015. Black Women-Owned Businesses: NWBC Analysis of 2012 Survey of Business Owners, National Women's Business Council. Washington, D.C.

Renzulli, L. A., Aldrich, H., and Moody, J. 2000. Family Matters: Gender, Networks, and Entrepreneurial Outcomes, Social Forces 79(2): 523-46. https://doi.org/10.2307/2675508

Reynolds-Dobbs, W., Thomas, K. M., \& Harrison, M. S. 2008. From Mammy to Superwoman: Images that Hinder Black Women's Career Development, Journal of Career Development 35(2):129-150. https://doi.org/10.1177/0894845308325645

Robinson, J., Blockson, L., \& Robinson, S. 2007. Exploring Stratification and Entrepreneurship: African American Women Entrepreneurs Redefine Success in Growth Ventures, The ANNALS of the American Academy of Political and Social Science 613(1): 131-154. https://doi.org/10.1177/0002716207303586

Robles, B. J., \& Cordero-Guzmán, H. 2007. Latino Self-employment and Entrepreneurship in the United States: An Overview of the Literature and Data Sources, The Annals of the American Academy of Political and Social Science 613(1): 18-31. https://doi.org/10.1177/0002716207303541

Ruef, M. 2010. The Entrepreneurial Group: Social Identities, Relations, and Collective Action. Princeton, NJ: Princeton University Press.

Silverman, R. M. 1999. Ethnic Solidarity and Black Business, American Journal of Economics and Sociology 58(4): 829-841. https://doi.org/10.1111/j.1536-7150.1999.tb03396.x

U.S. Department of Education. 2017. Status and Trends in the Education of Racial and Ethnic Groups 2017 (NCES 2017-051), National Center for Education Statistics.

West, L. M., Donovan, R. A., \& Daniel, A. R. 2016. The Price of Strength: Black College Women's Perspectives on the Strong Black Woman Stereotype, Women \& Therapy 39(3/4): 390-412. https://doi.org/10.1080/02703149.2016.1116871

Wingfield, A. 2007. The Modern Mammy and the Angry Black Man: African American Professionals' Experiences with Gendered Racism in the Workplace, Race, Gender \& Class 14(1/2): 196-21. 
Taylor M. Jackson is a doctoral candidate in Sociology at Florida State University. Her research interests include race, gender, work, organizations, and media representation. She is currently working on research examining Black women's self-care discourse online.

Paromita Sanyal, Ph.D., is associate professor of Sociology at Florida State University. She is a qualitative sociologist who specializes in the study of development, gender, political sociology, and economic sociology. She has been researching public participation in grassroots political institutions in Indian democracy and the impacts of microcredit programs and self-help groups on economically disadvantaged women in India. Her research has been published in her award-winning book Credit to Capabilities: A Sociological Study of Microcredit Groups in India (Cambridge University Press, 2014) and Oral Democracy (Cambridge University Press, 2018). She has also published articles in the American Sociological Review, Social Forces, Qualitative Sociology, and The Annals of the American Academy of Political and Social Sciences. 